\title{
Chromatin status and transcription factor binding to gonadotropin promoters in gonadotrope cell lines
}

Huimin Xie ${ }^{1 \dagger}$, Hanne M. Hoffmann ${ }^{1 \dagger}$, Anita K. Iyer ${ }^{1,2}$, Melissa J. Brayman ${ }^{1,3}$, Cindy Ngo ${ }^{1}$, Mary Jean Sunshine ${ }^{1}$ and Pamela L. Mellon ${ }^{1 *}$

\begin{abstract}
Background: Proper expression of key reproductive hormones from gonadotrope cells of the pituitary is required for pubertal onset and reproduction. To further our understanding of the molecular events taking place during embryonic development, leading to expression of the glycoproteins luteinizing hormone (LH) and folliclestimulating hormone (FSH), we characterized chromatin structure changes, imparted mainly by histone modifications, in model gonadotrope cell lines.

Methods: We evaluated chromatin status and gene expression profiles by chromatin immunoprecipitation assays, DNase sensitivity assay, and RNA sequencing in three developmentally staged gonadotrope cell lines, aT1-1 (progenitor, expressing Cga), aT3-1 (immature, expressing Cga and Gnrhr), and L $\beta T 2$ (mature, expressing Cga, Gnrhr, Lhb, and Fshb), to assess changes in chromatin status and transcription factor access of gonadotrope-specific genes.

Results: We found the common mRNA a-subunit of LH and FSH, called Cga, to have an open chromatin conformation in all three cell lines. In contrast, chromatin status of Gnrhr is open only in aT3-1 and L $\beta T 2$ cells. Lhb begins to open in L $\beta T 2$ cells and was further opened by activin treatment. Histone $\mathrm{H} 3$ modifications associated with active chromatin were high on Gnrhr in aT3-1 and L $\angle T 2$, and $L h b$ in $L \beta T 2$ cells, while H3 modifications associated with repressed chromatin were low on Gnrhr, Lhb, and Fshb in L $\beta T 2$ cells. Finally, chromatin status correlates with the progressive access of LHX3 to Cga and Gnrhr, followed by PITX1 binding to the Lhb promoter. Conclusion: Our data show the gonadotrope-specific genes Cga, Gnrhr, Lhb, and Fshb are not only controlled by developmental transcription factors, but also by epigenetic mechanisms that include the modulation of chromatin structure, and histone modifications.
\end{abstract}

Keywords: Epigenetic, DNA accessibility, Histone modification, Gonadotrope development, ChIP Assay, Chromatin

\section{Background}

The pituitary arises from the closure of Rathke's pouch on mouse embryonic day 12 (E12.5), giving rise to five endocrine cell types: gonadotropes, lactotropes, corticotropes, thyrotropes, and somatotropes. The development of these specialized cells depends on a stringent temporal and spatial control of transcription factors $[1,2]$. The gonadotropes emerge late in development at $\sim \mathrm{E} 16.5$, and

\footnotetext{
*Correspondence: pmellon@ucsd.edu

${ }^{\dagger}$ Equal contributors

'Department of Reproductive Medicine, Center for Reproductive Science and Medicine, University of California, 9500 Gilman Drive La Jolla, San Diego, CA 92093-0674, USA

Full list of author information is available at the end of the article
}

comprise $\sim 10-20 \%$ of pituitary cells in adulthood. The major role of gonadotropes is to regulate puberty and fertility through the synthesis and secretion of luteinizing hormone ( $\mathrm{LH}$ ) and follicle-stimulating hormone (FSH). FSH and LH are dimeric glycoproteins, formed from an $\alpha$ and a $\beta$ subunit. The $\beta$ subunit is distinct for each hormone, and is transcribed from separate genes. Gonadotrope cells can be traced throughout pituitary development by the sequential appearance of early lineage markers. First the mRNA for the common $\alpha$-subunit of $\mathrm{LH}$ and FSH ( $C g a$, glycoprotein hormones also known as $\alpha \mathrm{GSU})$ is detectable at E11.5 in the mouse, followed by the nuclear receptor Steroidogenic Factor 1 (Sf1 or 
$N r 5 a 1)$, and the gonadotropin-releasing hormone receptor (Gnrhr). Finally, the gonadotropin hormone beta subunit mRNAs emerge at E16.5 for Lhb and E17.5 for Fshb [3].

Specification of cell fate is controlled by a combination of transcription factors acting on cis-regulatory elements, as well as epigenetic mechanisms that include the modulation of chromatin structure $[4,5]$. Gene activation and repression are specifically regulated through changes in chromatin structure imparted mainly by histone modifications and DNA methylation. Inactive genes typically display condensed chromatin that is resistant to DNaseI digestion, and show histone $\mathrm{H} 3$ deacetylation and methylation [6, 7]. Active genes and regulatory elements are often in an open chromatin conformation to facilitate binding of regulatory proteins.

The access of transcription factors to the chromatin requires the relaxation of chromatin, leading to an open conformation and increased sensitivity to DNAseI digestion [8-10]. The regulation of chromatin status is complex and its analysis requires multiple complementary approaches. Open chromatin is often associated with acetylation at histone $\mathrm{H} 3$ and tri-methylation at histone H3-lysine 4 (H3K4) [6, 7]. In addition, certain combinations of histone modifications are thought to distinguish different regions within a given gene, i.e., promoters versus enhancers. For example, active promoters show high levels of tri-methylation and low levels of monomethylation at H3K4; whereas enhancers show the opposite methylation pattern at H3K4 [11]. The dynamic nature of chromatine modifications, are key in they role to control chromatine compaction and gene expression. Indeed, histone deacetylases (HDAC) allow histone deacetylation, leading to chromatin compaction [12, 13]. The conversion of chromatin from an inactive to active state at genes involved in differentiation is thought to promote the maturation of progenitor and precursor cells, however the chromatin status changes taking place during gonadotrope maturation are still poorly understood due to the complex cell composition of the pituitary.

Molecular investigation of the regulation of gonadotrope gene expression has been greatly facilitated by the use of well-characterized, cultured cell lines that represent different maturation stages of gonadotropes [14-17]. The $\alpha \mathrm{T} 1-$ 1 cell line represents a progenitor to the gonadotrope and/or thyrotrope lineages [15] and expresses the single common glycoprotein hormone subunit gene, Cga [18]. The immature gonadotrope $\alpha \mathrm{T} 3-1$ cell line expresses both $C g a$ and Gnrhr, and the mature gonadotrope L $\beta \mathrm{T} 2$ cell line expresses all four gonadotrope-specific genes Cga, Gnrhr, Lhb, and Fshb $[5,15,19,20]$. We and others have previously shown that these unique cell lines are excellent model systems for investigating the molecular mechanisms of gonadotrope differentiation [5, 15, 19, 21-26]. Moreover, these cell lines express the known tissue- specific regulators of the four gonadotrope-specific differentiated target genes including Sf1, Lhx3, Pitx1, Runx, Foxl2, and Gata2 [22, 24, 25, 27-31], and their binding sites in the proximal promoters of the gonadotropespecific genes have been defined either experimentally or bioinformatically $[5,29,32-34]$. These tissue-specific transcription factors play direct roles in regulating the transcription of the gonadotrope-specific target genes, yet the coordinated program of gonadotrope maturation remains to be elucidated [35, 36]. Recent work has begun to address this topic by analyzing the epigenetic regulation of gonadotrope specific genes [5]. To further our understanding of the global chromatin status of the gonadotrope-specific genes during gonadotrope maturation, and obtain a more comprehensive understanding of the changes in chromatin status allowing specific expression of key gonadotrope markers, we investigated chromatin status and its correlation to gonadotrope gene expression in our model pituitary lineage cell lines.

\section{Methods \\ Cell culture}

To establish how chromatin status on key gonadotrope genes changes during gonadotrope cell maturation, we studied three model immortalized mouse gonadotrope cell lines $\alpha \mathrm{T} 1-1$, $\alpha \mathrm{T} 3-1$, and L $\beta \mathrm{T} 2$, as well as two control cell lines, the mouse thyrotrope cell line T $\alpha \mathrm{T} 1$, and the mouse fibroblast cell line, NIH3T3 (ATCC). All cell lines were cultured in DMEM with $4.5 \%$ glucose (Mediatech Inc., Herndon, VA), $10 \%$ fetal bovine serum (Gemini Bio, West Sacramento, CA), and 1× penicillinstreptomycin (Life Technologies, Inc./Invitrogen, Grand Island, NY) in $5 \% \mathrm{CO}_{2}$ at $37{ }^{\circ} \mathrm{C}$. Cells were seeded on $10 \mathrm{~cm}$ dishes (Nunc, Roskilde, Denmark) and harvested at subconfluency. For hormone treatment of L $\beta T 2$ cells, cells were serum-starved for $16 \mathrm{~h}$ in DMEM containing $4.5 \%$ glucose, $1 \times$ penicillin-streptomycin and $0.1 \%$ bovine serum albumin. Cells were then treated for $4 \mathrm{~h}$ with $100 \mathrm{ng} / \mathrm{ml} \mathrm{GnRH}$ (Sigma-Aldrich, St. Louis, MO) $\pm 25 \mathrm{ng} / \mathrm{ml}$ activin (Calbiochem, La Jolla, CA) before they were harvested for the DNase sensitivity assay.

\section{DNase sensitivity assay}

Actively transcribed chromatin is characterized by being in an open conformation, allowing easy access of transcription factors to their binding sites. This open chromatin increases the sensitivity of the chromatin to DNaseI. To establish to what degree the gonadotrope promoters of model gonadotrope cell lines would increase their sensitivity to DNaseI treatment during maturation we performed a DNase sensitivity assay. DNase sensitivity assay was performed as previously described [37]. In brief, $\alpha \mathrm{T} 1-1, \alpha \mathrm{T} 3-1, \mathrm{~L} \beta \mathrm{T} 2$, and NIH3T3 cells were lysed in hypotonic buffer and nuclei were isolated 
by centrifugation at $2200 \mathrm{~g}$ for $5 \mathrm{~min}$ at $4{ }^{\circ} \mathrm{C}$. Intact nuclei were resuspended in $1 \mathrm{X}$ DNaseI Reaction Buffer (Promega, Madison, WI) containing 2\% glycerol. Equal amounts of nuclei were added to increasing quantities of DNaseI (Promega) in 1X DNase Reaction Buffer, ranging from 0 units $(\mathrm{U})$ to $7.5 \mathrm{U}$, and incubated at $37{ }^{\circ} \mathrm{C}$ for $5 \mathrm{~min}$. DNaseI was inactivated using DNaseI Stop Solution (Promega) and incubation at $65{ }^{\circ} \mathrm{C}$ for $10 \mathrm{~min}$. Treated nuclei were lysed in Nuclei Lysis Buffer followed by RNase A and Proteinase K digestion. Genomic DNA was then isolated by extraction twice with phenol/ chloroform/isoamyl alcohol and once with chloroform. DNA was ethanol precipitated and resuspended in TrisEDTA buffer followed by $55^{\circ} \mathrm{C}$ incubation for one hour. qPCR was performed using SYBR Green supermix and an iQ5 real-time PCR machine (BioRad). Primer sequences are detailed in Table 1. Forty ng of DNA from each treatment condition was quantitated relative to a standard curve of dilutions of undigested DNA. Data from each primer set were normalized to the active gene, $A c t b$, or to the vehicle treatment as stated in the figure legends [37].

\section{Chromatin immunoprecipitation (ChIP)}

To evaluate transcription factor binding to key gonadotrope gene promoters, we performed ChIP assays. ChIP assays were performed as previously described [38]. Chromatin was sonicated to an average length of $300-500 \mathrm{bp}$ using a Branson Sonifier 250 (Branson Ultrasonics Corp., Danbury, CT). Antibodies recognizing specific histone modifications were: anti-acetyl-Histone-H3 (06-599; Millipore, Temecula, CA), anti-trimethyl-Histone H3Lys4 (07-473; Millipore), anti-dimethyl-Histone H3-Lys9 (ab1220; Abcam), all of which are ChIP-grade antibodies.
To recognize phosphorylated polymerase, ChIP-grade anti-RNA polymerase II CTD repeat YSPTSPS (phospho S5) (ab5131; Abcam, Cambridge, MA), was used. Immunoprecipitated DNA and DNA from input chromatin were analyzed for sequences of interest by qRT-PCR using promoter-spanning primers specified in Table 1. For ChIP assays comparing $\alpha \mathrm{T} 1-1, \alpha \mathrm{T} 3-1$, and L $\beta$ T2 chromatin, the percentage of enrichment of antibody signal over IgG was calculated for each primer set. IgG was the same species and source as the comparison antibody. Then, values for activating chromatin marks were normalized to those for the inactive gene Gnrh1. For repressive chromatin marks, values were normalized to the highly active gene Actb [37-39].

\section{Association of transcription factors by ChIP}

Antibodies were ChIP grade or previously validated for ChIP assays: anti-LHX3 (L2202, US Biological, MA) [25], anti-PITX1 (sc-18,922X, Santa Cruz, ChIP grade). Immunoprecipitated DNA was analyzed for sequences of interest by qRT-PCR using promoter-specific primers shown in Table 1. For ChIP assays comparing $\alpha \mathrm{T} 1-1$, $\alpha \mathrm{T} 3-1$, and L $\beta \mathrm{T} 2$ chromatin, the percentage of enrichment of antibody signal over IgG was calculated for each primer set. Values were then normalized to those for the inactive gene Gnrh1 [37, 38].

\section{RNA sequencing}

To establish if gene expression levels in the studied cell lines correlated with chromatin status, we performed RNA sequencing. RNA was isolated from $\alpha \mathrm{T} 1-1, \alpha \mathrm{T} 1-$ 3, L $\beta$ T2, T $\alpha \mathrm{T} 1$, and NIH3T3 cells using TRIzol ${ }^{\circ}$ (Invitrogen, Grand Island, NY), as per the manufacturer's instructions, and treated with Turbo DNA-free DNase

Table 1 Primers used for qRT-PCR for ChIP and DNase sensitivity assays

\begin{tabular}{|c|c|c|c|c|c|}
\hline \multicolumn{2}{|l|}{ Primer } & \multirow[t]{2}{*}{ Product length } & \multirow[t]{2}{*}{ Chrom-osome } & \multicolumn{2}{|l|}{ Localization } \\
\hline Name & Sequence $\left(5^{\prime}-3^{\prime}\right)$ & & & Start & End \\
\hline Actb-F & GGCCAGCGTTTGCСTTTTATGGTAАTAАT & 181 & 5 & $142,905,689$ & $142,905,869$ \\
\hline \multicolumn{6}{|c|}{ Actb-R CGAACTATCAAGACACAAAAGAAGGCTATA } \\
\hline Fshb-F & GGTGTGCTGCCATATCAGATTCGG & 280 & 2 & $107,059,594$ & $107,059,873$ \\
\hline \multicolumn{6}{|c|}{ Fshb-R GCATCAAGTGCTGCTACTCACСTGTG } \\
\hline Gnrh-F & CAGCAGGTGTTGCAАTTACАTTCACСАTTAАG & 227 & 14 & $67,745,100$ & $67,745,326$ \\
\hline \multicolumn{6}{|c|}{ Gnrh-R CСTGTTTGGATGTGAAAGTCAAAGGGATCTC } \\
\hline Cga-F & GAAAATGGCCAAATGCTCTC & 193 & 4 & $34,893,533$ & $34,893,725$ \\
\hline \multicolumn{6}{|c|}{ Cga-R TGTTCCCAGCTGCACATAAG } \\
\hline Lhb-F & CGAGTGTGAGGCCAATTCACTGG & 218 & 7 & $45,420,767$ & $45,420,984$ \\
\hline \multicolumn{6}{|c|}{ Lhb-R GGGCССТАССАТСTTACСTGGAGC } \\
\hline Gnrhr-F & ATCAGAAGTAACAGGGACTCCACTC & 202 & 5 & $86,197,672$ & $86,197,873$ \\
\hline Gnrhr-R & AGTAGAGAGTAGGAAAAGGAAG & & & & \\
\hline
\end{tabular}

Localization and product length (bp) from the UCSC Genome Browser using the Mouse Dec. 2011 (GRCm38/mm10) Assembly. 
(Ambion, Life Technology, USA). The RNA integrity (RNA Integrity Number $\geq 9$ ) and quantity was determined on the Agilent 2100 Bioanalyzer (Agilent, Palo Alto, CA, USA). cDNA libraries $(n=2)$ were created using the TruSeq ${ }^{\text {ti }}$ RNA Sample Prep-v2 (Illumina, San Diego, CA), using the manufacturer's low-throughput protocol. Indexed samples were mixed at equal concentrations, four samples per lane, and sequenced using the HiSeq 2000 sequencer (Illumina). The resulting sequences were aligned to the mouse genome using the Illumina Consensus Assessment of Sequence and Variation (CASAVA) software program. qRT-PCR, sequencing, and alignment were performed by the UCSD BIOGEM Core facility supported by NIH grants P30 DK063491 and P30 CA023100. Thirty-six bp, single end sequencing of the five cell lines generated an average of 3.6 GB of sequencing data per sample with the following characteristics: NIH3T3: 852.2 Mbp, 23.67 million reads and passing filter \% (PF\%) of 75.6; $\alpha \mathrm{T} 1-1$ : reads, $\alpha \mathrm{T} 3-1$ : 933.2 Mbp, 25.92 million reads and $\mathrm{PF} \%$ of 75.2 ; $\mathrm{L} \beta \mathrm{T} 2$ : 897.0 Mbp, 24.92 million reads and PF\% of 67.8; and T $\alpha \mathrm{T} 1:$ 887.4 Mbp, 24.65 million reads and PF\% of 70.7 .

\section{Statistical analysis}

All experiments were repeated independently at least three times. In the figures, the error bars represent the SEM. Data were analyzed by one or two-way ANOVA in GraphPad Prism 7 (La Jolla, CA). For all analyses, the result was considered significant if $P \leq 0.05$.

\section{Results}

Chromatin density on gonadotrope-specific genes during development

To confirm that the immortalized pituitary cell lines expressed the key pituitary lineage markers and provide direct quantitation of expression levels, we performed RNA sequencing. We found that all five of the cell lines expressed high levels of $\beta$-actin (Fig. 1a, Actb). As expected, the common gonadotrope hormone $\alpha$ subunit, Cga, was expressed in all the gonadotrope lineage cell lines, as well as the thyrotrope cell line, T $\alpha \mathrm{T} 1[15,18]$, but not in NIH3T3 cells (Fig. 1a). The immature ( $\alpha \mathrm{T} 3-1)$ and mature (L $\beta$ T2) pituitary cell lines both expressed Gnrhr, whereas the gonadotrope marker, $L h b$, was only expressed by L $\beta \mathrm{T} 2$ cells. The thyrotrope cell line T $\alpha \mathrm{T} 1$ [18] was the

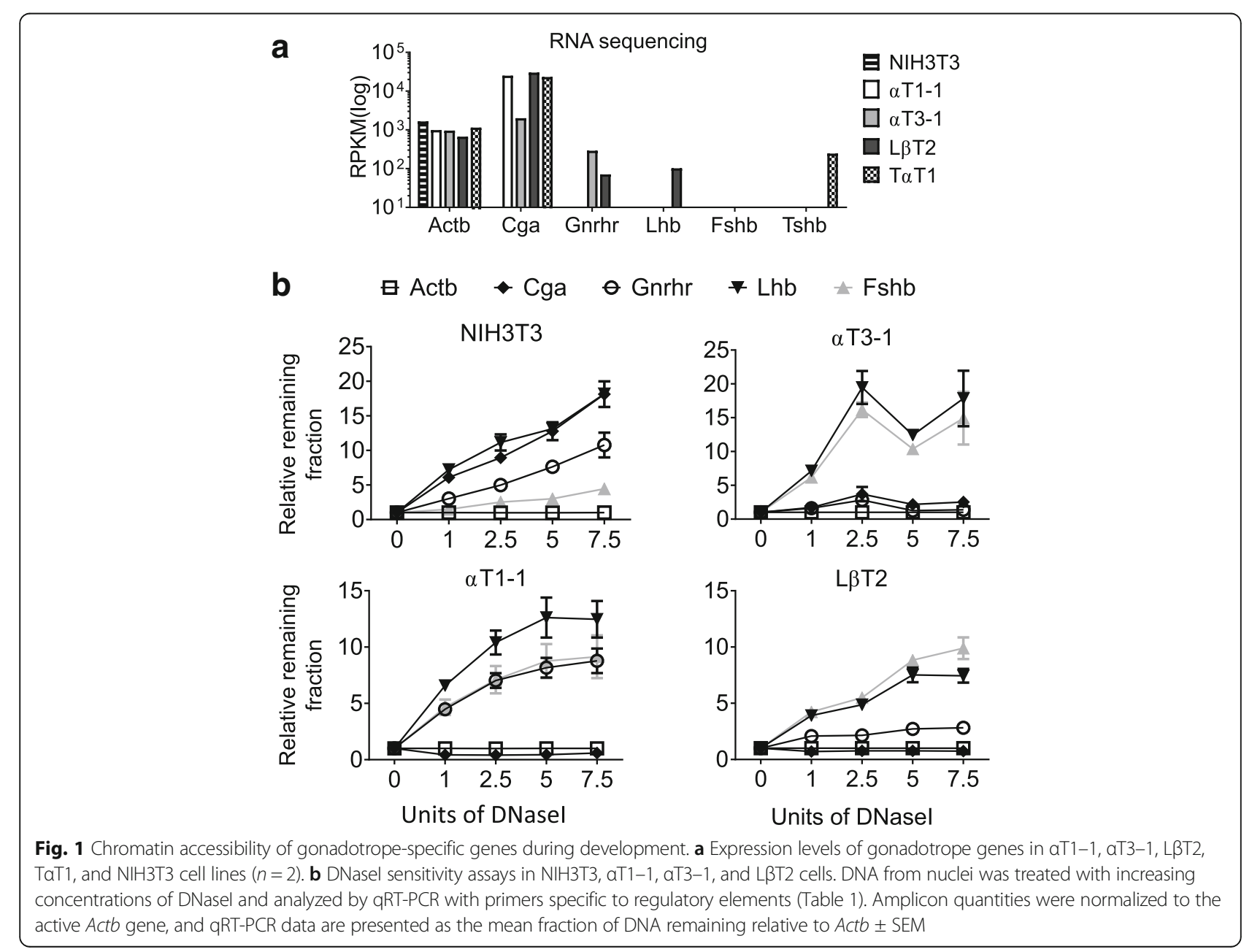


only cell line studied expressing the thyrotrope marker $T s h b$, and did not express any of the gonadotrope-specific genes, other than the common $\alpha$ subunit, Cga (Fig. 1a). We did not detect Fshb in L $\beta \mathrm{T} 2$ cells, although these cells are known to express this mRNA as detected by the more sensitive method of qRT-PCR. Fshb is found at low levels that can be induced by activin treatment [19, 40, 41]. NIH3T3 cells were used as a negative control for pituitary gene expression (Fig. 1a).

To determine if chromatin status correlates with expression of gonadotrope genes, we investigated the chromatin status by DNaseI sensitivity assay [42]. We focused on chromatin accessibility of Cga, Gnrhr, Lhb, and $F s h b$ in the gonadotrope lineage cell lines $\alpha \mathrm{T} 1-1$, $\alpha \mathrm{T} 3-1$, and L $\beta \mathrm{T} 2$, which represent different stages of gonadotrope development. NIH3T3 cells were used as a negative control. Actb ( $\beta$-actin) is ubiquitously expressed in all the above cell lines, reflecting an open chromatin status, and was therefore used to normalize the DNaseI data (Fig. 1a and b, Actb). Three classes of chromatin accessibility have been determined by this assay: closed (repressed), poised, and open (active) [43, 44]. One of the characteristics of chromatin is how dynamic its conformation is, and its capacity to compact and unfold. Thus, degrees of compaction and opening of the DNA are possible. Normalizing our data to the highly transcribed Actb allowed us to determine the relative DNaseI sensitivity of the studied gonadotrope genes. To reveal the degree of accessibility of the DNA, we used increasing amounts of DNaseI. As expected, we found that $C g a$, $L h b$, and Gnrhr were much less sensitive to DNaseI treatment than Actb (Fig. 1b), which correlated with gene expression levels (Fig. 1a). Unexpectedly, Fshb was sensitive to DNaseI treatment, although to a lesser extent than Actb (Fig. 1b). However this did not correlate with gene transcription (Fig. 1a), supporting the importance of using more than one approach to study chromatin status to obtain a complete image of chromatin accessibility to transcription factors. Cga is the earliest gonadotrope expressed gene (E11.5 in the mouse embryo) and has high expression in the gonadotrope progenitor $\alpha \mathrm{T} 1-1$ cell line (Fig. 1a). Consistent with this, we found an open chromatin structure in the promoter region of Cga in this cell line (Fig. 1b, $\alpha \mathrm{T} 1-1)$. The chromatin states of all other later chromatin modifications of gonadotrope cell lines were repressed as evidenced by their structures being closed and resistant to DNaseI degradation (Fig. 1b, $\alpha \mathrm{T} 1-1$, Fshb, Lhb and Gnrhr). The immature gonadotrope cell-line $\alpha \mathrm{T} 3-1$ expresses both Cga and Gnrhr (Fig. 1a). In agreement with this, we determined the chromatin state of these genes to be open (Fig. 1b, $\alpha \mathrm{T} 3-1$ ). Lhb and Fshb are not expressed in the $\alpha \mathrm{T} 3-1$ cells and have closed chromatin in this cell (Fig. 1a). Our data show that the chromatin of Lhb and
Fshb started to shift from closed to poised in the L $\beta \mathrm{T} 2$ cells (Fig. 1b, LßT2, Two-way ANOVA, followed by Sidaks multiple comparison, $p>0.01$ at 7.5 Units of DNaseI). The only partial opening of $L h b$ and Fshb in L $\beta$ T2 cells is not surprising, as cells in culture are not in the tridimensional environment they experience in vivo and do not receive hormonal stimulation, as gonadotropes would in vivo, allowing them to fully activate expression of Lhb and Fshb.

\section{Chromatin modifications of gonadotrope-specific genes during development}

Numerous modifications of chromatin and histones allow for successful recruitment of phosphorylated RNA polymerase II (phospho-Pol II), which is required to initiate transcription [10]. To determine if the opening of the chromatin in these cell lines correlates with a change in the acetylation and methylation signatures on the histones binding to the promoters and allows occupation with phospho-Pol II, we next performed ChIP assays. We used antibodies recognizing the activating histone modification marks histone $\mathrm{H} 3$ acetylation (H3Ac), and H3K4 trimethylation (H3K4Me3, Fig. 2), as well as recruitment of phospho-Pol II [38, 44]. Although, Cga is highly expressed by all three gonadotrope lineages (Fig. 1a), and the promoter is sensitive to DNaseI treatment (Fig. 1b), the active histone marks in all three cell lines were surprisingly little enriched as compared to Gnrh1, despite recruitment of phospho-Pol II and active transcription (Fig. 1a and 2a). This is unexpected and is possibly due to the chosen region of study of the Cga promoter. In agreement with both transcription levels of Gnrhr, and its promoter's sensitivity to DNaseI treatment, the Gnrhr regulatory region went from possessing very few active histone marks in $\alpha \mathrm{T} 1-1$, to highly enriched in these marks in $\alpha \mathrm{T} 3-1$ and L $\beta$ T2 cells (Fig. 2). In agreement with our findings using the DNaseI sensitivity assay, which found the Fshb promoter to be in a rather closed conformation (Fig. 1b), this promoter exhibits only one of the chromatin marks of an open promoter (H3Ac), but does not bind phosphorylated polymerase II (Fig. 2). Finally, the chromatin status of $L h b$ is enriched in H3Ac and recruits phosphorylated polymerase II to the regulatory region somewhat in $\alpha \mathrm{T} 3-1$ and more strongly in L $\beta \mathrm{T} 2$, which correlated with transcription in L $\beta$ T2 cells where it also exhibits enrichment of H3K4Me3 (Fig. 1a and 2).

To assess the epigenetic role of repression, we performed ChIP assays to analyze the repressive histone modifications H3K9Me2 and H3K27Me3 [45]. We found that one or both modifications were reduced with developmental maturation on the promoters of Gnrhr and $L h b$ (Fig. 3). Gnrhr loses both repressive marks in $\alpha \mathrm{T} 3-1$ and L $\beta$ T2 cells, while Lhb has progressively reduced H3K27Me3 from $\alpha \mathrm{T} 1-1$ to $\alpha \mathrm{T} 3-1$ and finally L $\beta \mathrm{T} 2$ and 


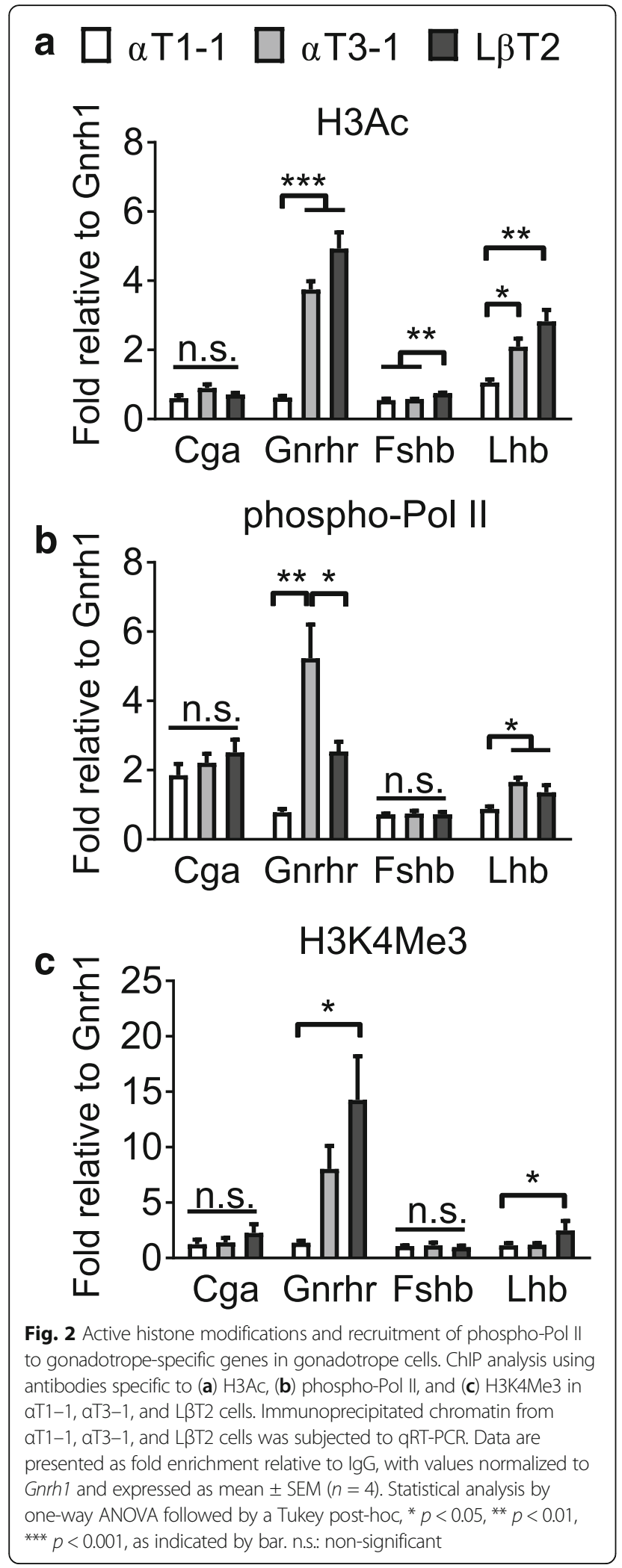

trends toward lower H3K9Me2 in L $\beta \mathrm{T} 2$ cells (Fig. 3). Whereas no changes were observed on the $F s h b$ promoter (Fig. 3).

\section{Sequential recruitment of developmental pituitary} transcription factors to gonadotrope-specific promoters Opening of the chromatin, along with activating histone modifications, promotes access to the chromatin of transcription factors. It has previously been shown that the known gonadotrope regulatory proteins PITX2 (Pitx2), SF1 (Nr5r1), and LHX3 ( $h h \times 3)$ control expression of the mature gonadotrope markers Lhb, Fshb, and Gnrhr $[25,46,47]$. Using RNA sequencing, we show that these transcription factors are expressed in the gonadotrope lineage and thyrotrope cell lines, but not in NIH3T3

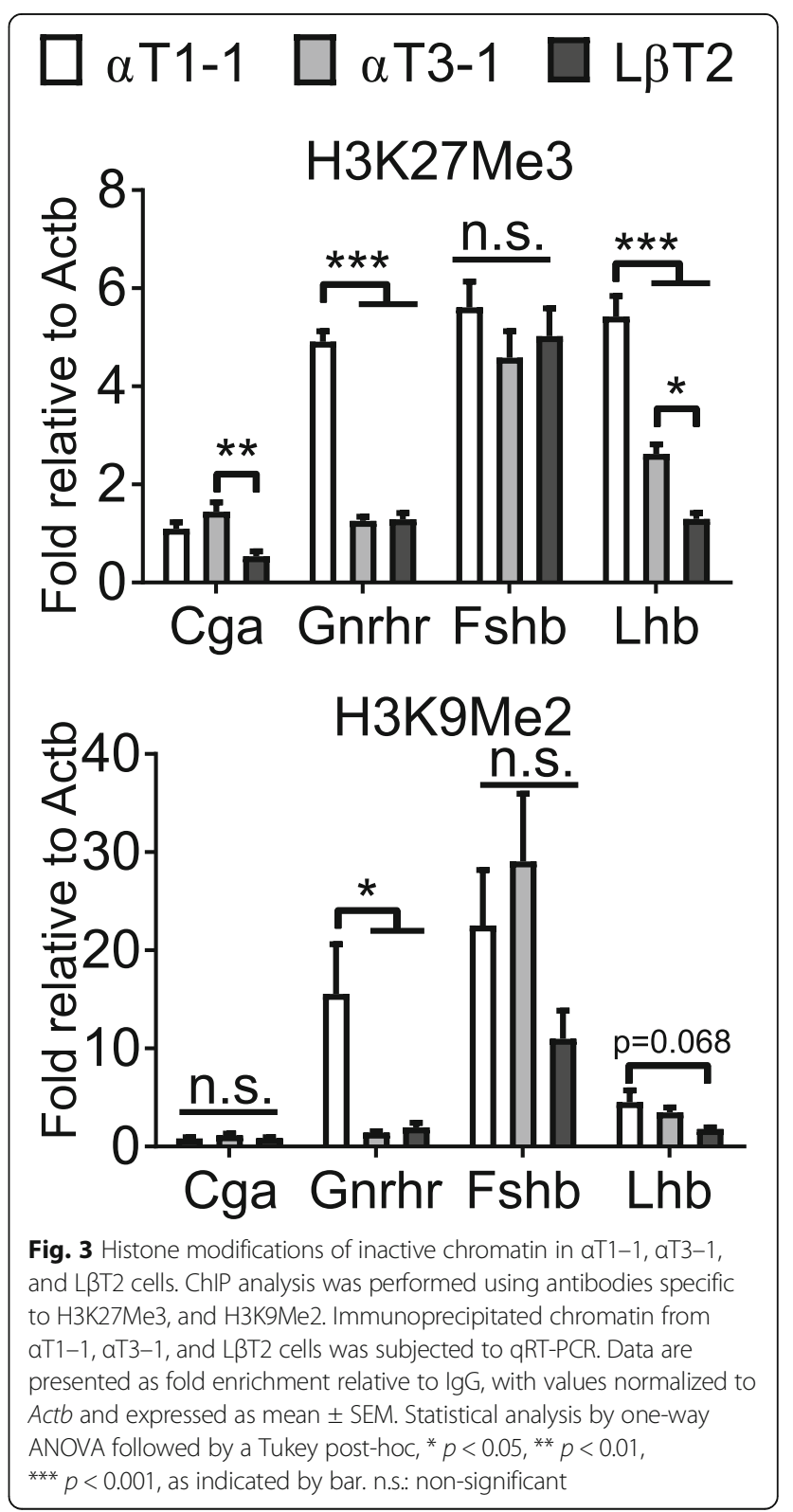


cells (Fig. 4a). Appropriately, the gonadotrope-specific transcription factor SF1 is not expressed in thyrotropes $(\mathrm{T} \alpha \mathrm{T} 1)$ or in the gonadotrope progenitor cells $(\alpha \mathrm{T} 1-1)$. To test whether the gonadotrope-specific regulatory factors, LHX3 and PITX1, are associated with regulatory regions of gonadotrope promoters in any of the studied cell lines, we performed a ChIP analysis using LHX3 and PITX1 antibodies. ChIP analysis revealed that both transcription factors can bind on the gonadotrope terminal target genes (Fig. 4b, c). LHX3 is able to bind the promoter of Cga and Gnrhr, but neither $L h b$ nor Fshb exhibit binding by this method, at any of the stages of development (Fig. 4b, LHX3). PITX1 binds the gonadotrope-specific promoters $C g a$ and $L h b$, but not Gnrhr nor Fshb in this assay (Fig. 4c). This suggests the program of differentiation in these cells is not regulated simply by deacetylated histones [48], but more likely requires a timed balance of transcription factors, co-factors, histone modifications, DNA methylation, and/or networks to control the developmental gonadotrope gene expression program.

To extend this further, we asked if the final differentiation of the gonadotrope lineage cells required $\mathrm{GnRH}$ and/or activin treatment for the proper expression of mature gonadotrope genes. We serum starved L $\beta$ T2 cells for $16 \mathrm{~h}$ then treated them for $4 \mathrm{~h}$ with $100 \mathrm{ng} / \mathrm{ml}$
GnRH $\pm 25 \mathrm{ng} / \mathrm{ml}$ activin and assayed the chromatin status of the $L h b$ promoter for DNase sensitivity. Indeed, activin with or without GnRH treatment promoted $L h b$ promoter opening (Fig. 4d, Two-way ANOVA compared to vehicle, $p>0.05$ for activin at 2 and 5 units of DNaseI, and $p>0.01$ for activin $+\mathrm{GnRH}$ at 2 and 5 units of DNaseI, $p<0.05$ when comparing activin to activin $+\mathrm{GnRH})$. Lhb is known to be induced by either $\mathrm{GnRH}$ or activin [23]. In contrast, these treatments did not change chromatin opening of the already opened $C g a$ and Gnrhr promoters and could not change the chromatin status of Fshb (data not shown).

\section{Discussion}

Elucidation of the molecular and cellular mechanisms underlying pituitary development and cellular specification is critical to our understanding of reproduction and infertility. Herein, we used three immortalized pituitary cell lines, which have been shown to model many aspects of developing gonadotropes [15, 20,49]. It is clear that epigenetic regulation of chromatin is key in correct gene expression and cellular maturation. In this study, we present data showing that pituitary gonadotrope cell lines reveal epigenetic programming that allows the sequential expression of pituitary hormone genes in differentiation (Fig. 5).

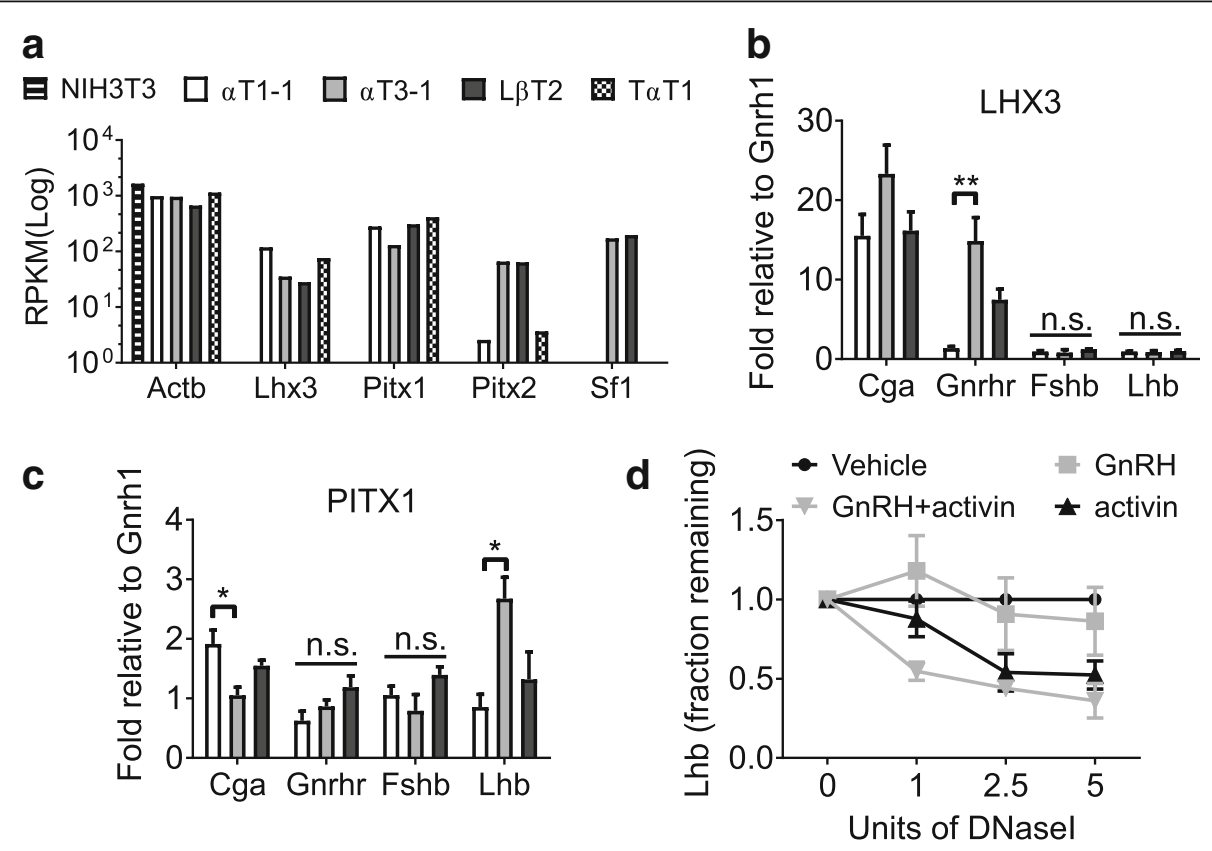

Fig. 4 Pituitary transcription factor accessibility in developing gonadotrope cell lines. a Expression levels of transcription factors in NIH3T3, aT1-1, aT3-1, L $\beta T 2$, and TaT1 cell lines $(n=2)$. ChIP assays in aT1-1, aT3-1, and L $\beta T 2$ cells were performed using antibodies specific to the transcription factors (b) LHX3 and (c) PITX1. Immunoprecipitated chromatin was subjected to qRT-PCR. Data are presented as fold enrichment relative to lgG, with values normalized to Gnrh1 and expressed as mean \pm SEM. Statistical analysis by one-way ANOVA followed by a Tukey post-hoc, ${ }^{*} p<0.05$, ${ }^{* *} p<0.01$, as indicated by bar. n.s.: non-significant. $\mathbf{d} L \beta T 2$ cells were treated with $\mathrm{GnRH}$ and/or activin $(n=3)$, before DNA from nuclei were treated with increasing concentrations of DNasel and analyzed by qRT-PCR with primers specific to Lhb. Amplicon quantities were normalized to untreated samples (Vehicle), and data presented as the mean fraction of DNA remaining relative to vehicle 


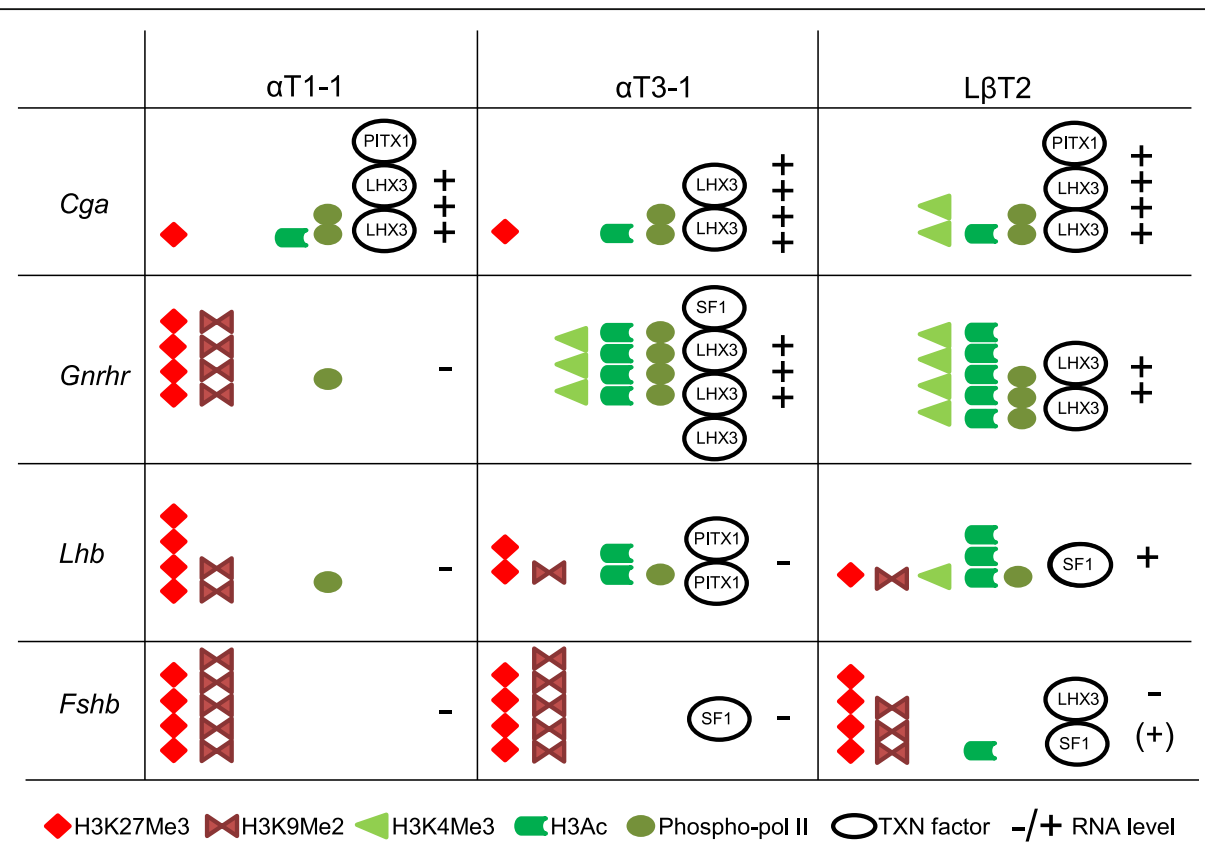

Fig. 5 Summary of gonadotrope gene transcription, transcription factor occupancy and chromatin changes in gonadotrope cells. During gonadotrope maturation, illustrated here by the progenitor aT1-1, immature aT3-1, and mature L $\beta T 2$ cells, the chromatin status changes from a closed conformation on Gnrhr, Lhb and Fshb (enrichment in H3K27Me3 and H3K9Me2) in aT1-1, to a more open conformation in L $\beta T 2$ cells (increase in H3Ac, and H3K4Me3), which is associated with enhanced expression of Lhb and Gnrhr (+). The progressive opening of the Lhb promoter allows recruitment of the transcription factors (TXN factors) PITX1 and SF1 [68], whereas opening of the Gnrhr promoter allows recruitment of SF1 and LHX3 [69]. The regulatory region of the a-subunit Cga is in an open confirmation during all the stages of maturation, and associated with recruitment of PITX1 and LHX3 and high mRNA expression (+++). The discrete opening of the Fshb promoter during gonadotrope maturation allows association of SF1 and LHX3 to the regulator region of Fshb [70, 71]. Depending on study conditions, Fshb transcript is undetectable or can be detected at low levels in L $\beta T 2$ cells

The anterior pituitary has five different endocrine cell types: gonadotropes, lactotropes, corticotropes, thyrotropes, and somatotropes. Until now, no efficient method has been established to isolate live gonadotropes for in vitro cell culture. We have previously used the Ribotag technique, which allows selection of ribosomeassociated mRNAs of specific cell-types, to isolate gonadotrope mRNAs and process them for qRT-PCR $[50,51]$. However, as we were interested in comparing effects of hormone treatments and transcription factors on chromatin status, we performed this study in model gonadotrope cell lines. We used the developmentally staged gonadotrope cell lines, progenitor $\alpha \mathrm{T} 1-1$, immature $\alpha \mathrm{T} 3-1$, and mature L $\beta \mathrm{T} 2$ cell models to address the epigenetic regulation status of gonadotrope-specific genes (Cga, Gnrhr, Fshb, and $L h b)$ during gonadotrope maturation.

Studies of the chromatin state of Cga shows that it is open at a very early stage represented by $\alpha \mathrm{T} 1-1$ cells, while Gnrhr chromatin opens at an immature developmental stage represented by $\alpha \mathrm{T} 3-1$. These correlate directly with recruitment of phospho-Pol II and mRNA expression (Fig. 5). The $L h b$ and Fshb genes only begin to show relaxation of chromatin status in the more developmentally mature cell lines, $\alpha \mathrm{T} 3-1$ and $\mathrm{L} \beta \mathrm{T} 2$. This opening of the chromatin correlates with the appearance of positive, and loss of negative, histone modifications, which correlates with specific gene expression. We found that both Gnrhr and Lhb, though not Fshb, have progressive increases in phospho-Pol II, H3Ac and/or $\mathrm{H} 3 \mathrm{~K} 4 \mathrm{Me} 3$, as well as a loss of $\mathrm{H} 3 \mathrm{~K} 27 \mathrm{Me} 3$ and/or $\mathrm{H} 3 \mathrm{~K} 9 \mathrm{Me} 2$ from the progenitor $\alpha \mathrm{T} 1-1$ and immature $\alpha \mathrm{T} 3-1$, to the mature L $\beta \mathrm{T} 2$ (Fig. 5). This partial correlation between chromatin state and gene transcript levels was recently described in $\alpha \mathrm{T} 1-1, \alpha \mathrm{T} 3-1$, and $\mathrm{L} \beta \mathrm{T} 2$ cells, where Laverriere et al. were unable to detect Fshb and found the $L h b$ promoter to be equally sensitive to DNaseI treatment in $\alpha \mathrm{T} 1-1, \alpha \mathrm{T} 3-1$, and $\mathrm{L} \beta \mathrm{T} 2$, despite transcription of $L h b$ specifically in L $\beta \mathrm{T} 2$ cells [5]. Interestingly, despite lack of $F s h b$ transcription in the mouse fibroblast cell line, NIH3T3, our DNaseI sensitivity assay found the $F$ shb regulatory region to be relatively sensitive to DNaseI. DNaseI Chip-seq of NIH3T3 cells has been done previously and is available on the USCS genome browser (consulted July 25, 2017). The deposited data set was generated using a different DNaseI protocol from ours, using a single DNaseI concentration, and showed the $F s h b$ and $L h b$ regulatory regions to be in relatively closed conformations. However, by comparing chromatin status and transcription factor occupancy of 
the Fshb regulatory region of numerous studies deposited on the USCS genome browser, we found the upstream region of $F s h b$ to be able to bind transcription factors including REST (repressor element-1 silencing transcription factor), which is a known repressor of transcription [52]. Thus, it is very likely that the DNaseI sensitivity of the Fshb regulatory region, in NIH3T3 cells in our assay, shows some degree of opening. In addition, approximately $1 \mathrm{~Kb}$ upstream of the transcriptional start site of $F s h b$ is a SINE repeat [53], which can allow expression in many different cell lines, and thus could confer a DNaseI sensitive region upstream of the Fshb gene. Interestingly, a SINE repeat has been found within intron 1 of the pig Fshb gene, which affects Fshb expression and reproductive function in pigs [54]. It will therefore be of interest in future studies to address the role of the SINE repeats upstream of the mouse Fshb transcription start site, to determine if these also impact Fshb expression in gonadotrope cell lines.

As expected, Cga, which is highly transcribed in all three cell lines, did not have significant differences between the cell lines in histone modifications or phospho-Pol II occupation. Although we and others [5] did not detect Fshb mRNA in any of the three studied cell lines without using highly sensitive qRT-PCR or activin treatment, Fshb does start to gain H3Ac histone modifications in L $\beta$ T2 cells as well. Since Fshb is detected at low levels, and only using qRT-PCR in L $\beta$ T2 cells [55], it is not unexpected that histone modifications may reflect a less active status (Fig. 5). We believe that the low expression of Fshb in L $\beta$ T2 cells is due to the relatively simple milieu in which the cell lines are maintained, in comparison to the broad range of stimuli and hormones received by gonadotropes in vivo. The low expression of $F s h b$ is possibly mediated by HDAC. It was previously shown that a GnRH treatment or inhibition of HDACs in $\alpha$ T3-1 cells allowed rapid expression of both $L h b$ and $F s h b$ [56]. This confirms that $\alpha$ T3-1 cells possess all of the required transcriptional machinery to initiate expression of $L h b$ and Fshb, but removal of HDACs, particularly HDAC4 from these promoters is required to actively transcribe $L h b$ and $F s h b$ [56]. Based on this, we hypothesized that hormonal treatment of L $\beta$ T2 cells would allow opening of the chromatin of these genes. Thus, we treated L $\beta$ T2 cells with activin \pm $\mathrm{GnRH}$. Indeed, activin significantly promoted $L h b$ promoter opening in L $\beta \mathrm{T} 2$ cells with or without GnRH, however we were unable to detect opening of the Fshb promoter in any of the studied conditions (not shown). As GnRH alone was inefficient in opening the chromatin of the $L h b$ promoter, perhaps due to the tonic as opposed to pulsatile treatment or the single time point of a 4-h exposure. GnRH does induce $L h b$ gene expression but may act without further opening the chromatin.
Prior studies have shown that an increase in GnRH pulse frequency favors $L h b$ expression [57, 58], while a decrease favors Fshb gene expression [59-61]. To further our understanding of chromatin status of gonadotrope genes, and their response to hormone treatment, it will be of interest to expand the presented studies using Chip-seq, which allows the study of enhancers as well as other regulatory regions, in combination with ATACseq, a technique which has been shown to be more precise than H3K27Ac in identifying active promoters [62].

To establish the relationship between molecular and epigenetic mechanisms in gonadotropes, we investigated the accessibility of the transcription factors, LHX3, and PITX1, to bind gonadotrope-specific gene promoters in the studied cell lines [63-67]. Interestingly, the regulatory proteins PITX1/2, SF1, and LHX3 were all present in the intermediate gonadotrope cell line $(\alpha \mathrm{T} 3-1)$, and some even in $\alpha$ T1-1 (PITX1/2, and LHX3). By comparing chromatin status and transcription factor access to the chromatin, our data indicate that LHX3 is important in early and maintained expression of Cga. In agreement with previous studies [25, 31], the opening of the Gnrhr promoter in $\alpha \mathrm{T} 3-1$ cells allowed increased association of LHX3 with the promoter, whereas the increased opening of the $L h b$ promoter correlated with recruitment of PITX1 (Fig. 5) [68]. In our hands, the Fshb promoter was in a rather closed configuration, not allowing detectable association of transcription factors with this gene.

\section{Conclusion}

Our data show exciting new evidence of gonadotropespecific chromatin changes taking place during development using immortalized model gonadotrope cell lines. Although the cell lines utilized remain an in vitro system, representative of developing gonadotrope cell lines, we show a progressive opening of the gonadotropespecific gene promoters, Cga, Gnrhr, Lhb, and Fshb in these model cell lines and demonstrate that these promoters are not only controlled by developmental transcription factors, but also by epigenetic mechanisms that include the modulation of chromatin structure, and histone modifications.

\begin{abstract}
Abbreviations
Actb: Beta actin; Cga: Glycoprotein hormones or aGSU; ChIP: Chromatin immunoprecipitation; E: Embryonic day; FSH: Follicle-stimulating hormone; Fshb: FSH beta subunit; GnRH: Gonadotrope-releasing hormone; GnRHR: Gonadotropin-releasing hormone receptor; H3Ac: H3 acetylation; H3K4: Histone H3-lysine 4; H3K4Me3: H3K4 trimethylation; HDAC: Histone deacetylases; LH: Luteinizing hormone; Lhb: LH beta subunit; phospho-Pol II: phosphorylated polymerase II; SF1: Steroidogenic Factor 1 or Nr5a1
\end{abstract}

\section{Acknowledgements}

The authors thank Crystal Trang for her assistance with this work and Dr. Dorota Skowronska-Krawczyk for assistance with UCSC databases. 


\section{Funding}

This work was supported by NIH grants R01 HD085267, R01 HD072754, and R01 HD020377 (to P.L.M.) and by NICHD/NIH P50 HD012303 as part of the National Centers for Translational Research in Reproduction and Infertility (P.L.M.). P.L.M. was partially supported by P30 DK063491, P42 ES101337, and P30 CA023100. H.X. was partially supported by T32 HD007203 and F32 HD070579. H.M.H. was partially supported by K99 HD084759. A.K.I. was partially supported by F32 HD058427 and T32 DK007494. M.J.B. was partially supported by F32 HD058460 and T32 HD007203. Funding sources had no role in this work.

\section{Availability of data and materials}

The datasets generated and analyzed during the current study are accessible through GEO Series accessionnumber GSE104513 (https:// www.ncbi.nlm.nih.gov/geo/query/acc.cgi?acc=GSE104513).

\section{Authors' contributions}

$H X, H M H$, and PLM wrote the manuscript. HX, AKI, MJB, HMH, and PLM designed the experiments, analyzed the data and discussed the results. $H X$ AKI, MJB, CN, and MJS performed the experiments. All authors read and approved the final version of the manuscript.

\section{Ethics approval and consent to participate}

Not applicable

\section{Consent for publication}

Not applicable

\section{Competing interests}

The authors declare that they have no competing interests.

\section{Publisher's Note}

Springer Nature remains neutral with regard to jurisdictional claims in published maps and institutional affiliations.

\section{Author details}

${ }^{1}$ Department of Reproductive Medicine, Center for Reproductive Science and Medicine, University of California, 9500 Gilman Drive La Jolla, San Diego, CA 92093-0674, USA. llumina Inc, 5200 Illumina Way, San Diego, CA 92122, USA. ${ }^{3}$ Foley and Lardner LLP, 402 West Broadway, Suite 2100, San Diego, CA 92101, USA.

Received: 28 March 2017 Accepted: 4 October 2017

Published online: 24 October 2017

\section{References}

1. Simmons DM, Voss JW, Ingraham HA, Holloway JM, Broide RS, Rosenfeld $M G$, et al. Pituitary cell phenotypes involve cell-specific Pit-1 mRNA translation and synergistic interactions with other classes of transcription factors. Genes Dev. 1990;4:695-711.

2. Scully KM, Rosenfeld MG. Pituitary development: regulatory codes in mammalian organogenesis. Science. 2002;295:2231-5.

3. Japon MA, Rubinstein M, Low MJ. In situ hybridization analysis of anterior pituitary hormone gene expression during fetal mouse development. J Histochem Cytochem. 1994;42:1117-25.

4. Hsieh J, Gage FH. Chromatin remodeling in neural development and plasticity. Curr Opin Cell Biol. 2005;17:664-71.

5. Laverriere JN, L'Hote D, Tabouy L, Schang AL, Querat B, Cohen-Tannoudji J. Epigenetic regulation of alternative promoters and enhancers in progenitor, immature, and mature gonadotrope cell lines. Mol Cell Endocrinol. 2016; 434:250-65.

6. Li B, Carey M, Workman JL. The role of chromatin during transcription. Cell. 2007;128:707-19.

7. Sims RJ 3rd, Nishioka K, Reinberg D. Histone lysine methylation: a signature for chromatin function. Trends Genet. 2003;19:629-39.

8. Gross DS, Garrard WT. Nuclease hypersensitive sites in chromatin. Annu Rev Biochem. 1988;57:159-97.

9. Shewchuk BM, Asa SL, Cooke NE, Liebhaber SA. Pit-1 binding sites at the somatotrope-specific DNase I hypersensitive sites I, II of the human growth hormone locus control region are essential for in vivo hGH-N gene activation. J Biol Chem. 1999;274:35725-33.
10. Venkatesh S, Workman JL. Histone exchange, chromatin structure and the regulation of transcription. Nat Rev Mol Cell Biol. 2015;16:178-89.

11. Heintzman ND, Stuart RK, Hon G, Fu Y, Ching CW, Hawkins RD, et al. Distinct and predictive chromatin signatures of transcriptional promoters and enhancers in the human genome. Nat Genet. 2007;39:311-8.

12. Hsieh J, Nakashima K, Kuwabara T, Mejia E, Gage FH. Histone deacetylase inhibition-mediated neuronal differentiation of multipotent adult neural progenitor cells. Proc Natl Acad Sci U S A. 2004;101:16659-64.

13. Siebzehnrubl FA, Buslei R, Eyupoglu IY, Seufert S, Hahnen E, Blumcke I. Histone deacetylase inhibitors increase neuronal differentiation in adult forebrain precursor cells. Exp Brain Res. 2007;176:672-8.

14. Windle JJ, Weiner Rl, Mellon PL. Cell lines of the pituitary gonadotrope lineage derived by targeted oncogenesis in transgenic mice. Mol Endocrinol. 1990;4:597-603.

15. Alarid ET, Windle JJ, Whyte DB, Mellon PL. Immortalization of pituitary cells at discrete stages of development by directed oncogenesis in transgenic mice. Development. 1996:122:3319-29.

16. Lew D, Brady H, Klausing K, Yaginuma K, Theill LE, Stauber C, et al. GHF-1 promoter-targeted immortalization of a somatotropic progenitor cell results in dwarfism in transgenic mice. Genes Dev. 1993;7:683-93.

17. Pernasetti F, Spady TJ, Hall SB, Rosenberg SB, Givens ML, Anderson S, et al. Pituitary tumorigenesis targeted by the ovine follicle-stimulating hormone beta-subunit gene regulatory region in transgenic mice. Mol Cell Endocrinol. 2003;203:169-83.

18. Yusta B, Alarid ET, Gordon DF, Ridgway EC, Mellon PL. The thyrotropin $\beta$ subunit gene is repressed by thyroid hormone in a novel thryrotrope cell line, mouse TaT1 cells. Endocrinology. 1998;139:4476-82.

19. Pernasetti F, Vasilyev W, Rosenberg SB, Bailey JS, Huang H-J, Miller WL, et al. Cell-specific transcriptional regulation of FSH $\beta$ by activin and $\mathrm{GnRH}$ in the LBT2 pituitary gonadotrope cell model. Endocrinology. 2001;142:2284-95.

20. Graham KE, Nusser KD, Low MJ. LBT2 gonadotroph cells secrete follicle stimulating hormone (FSH) in response to activin A. J Endocrinol. 1999:162:R1-5.

21. Bailey JS, Rave-Harel N, Coss D, McGillivray SM, Mellon PL. Activin regulation of the follicle-stimulating hormone $\beta$-subunit gene involves Smads and the TALE homeodomain proteins Pbx1 and Prep1. Mol Endocrinol. 2004;18: 1158-70.

22. Barnhart KM, Mellon PL. The orphan nuclear receptor, steroidogenic factor1 , regulates the glycoprotein hormone a-subunit gene in pituitary gonadotropes. Mol Endocrinol. 1994;8:878-85.

23. Coss D, Thackray VG, Deng CX, Mellon PL. Activin regulates luteinizing hormone beta-subunit gene expression through smad-binding and homeobox elements. Mol Endocrinol. 2005;19:2610-23.

24. Corpuz PS, Lindaman LL, Mellon PL, Coss D. FoxL2 is required for activin induction of the mouse and human follicle-stimulating hormone $\beta$-subunit genes. Mol Endocrinol. 2010;24:1037-51

25. McGillivray SM, Bailey JS, Ramezani R, Kirkwood BJ, Mellon PL. Mouse GnRH receptor gene expression is mediated by the LHX3 homeodomain protein. Endocrinology. 2005;146:2180-5.

26. Xie H, Hoffmann HM, Meadows JD, Mayo SL, Trang C, Leming SS, et al. Homeodomain proteins SIX3 and SIX6 regulate gonadotrope-specific genes during pituitary development. Mol Endocrinol. 2015;29:842-55.

27. Steger DJ, Hecht JH, Mellon PL. GATA-binding proteins regulate the human gonadotropin a-subunit gene in placenta and pituitary gland. Mol Cell Biol. 1994;14:5592-602

28. Rosenberg SB, Mellon PL. An Otx-related homeodomain protein binds an $\mathrm{LH} \beta$ promoter element important for activation during gonadotrope maturation. Mol Endocrinol. 2002;16:1280-98.

29. Harris AN, Mellon PL. The basic helix-loop-helix leucine zipper transcription factor USF is a key regulator of SF-1 gene expression in pituitary gonadotrope and steroidogenic cells. Mol Endocrinol. 1998;12:714-27.

30. Breen KM, Thackray VG, Coss D, Mellon PL. Runt-related transcription factors impair activin induction of the follicle-stimulating hormone beta-subunit gene. Endocrinology. 2010;151:2669-80.

31. Schang AL, Granger A, Querat B, Bleux C, Cohen-Tannoudji J, Laverriere JN. GATA2-induced silencing and LIM-homeodomain protein-induced activation are mediated by a bi-functional response element in the rat GnRH receptor gene. Mol Endocrinol. 2013;27:74-91.

32. Zubair M, Ishihara S, Oka S, Okumura K, Morohashi K. Two-step regulation of Ad4BP/SF-1 gene transcription during fetal adrenal development: initiation by a Hox-Pbx1-Prep1 complex and maintenance via autoregulation by Ad4BP/SF-1. Mol Cell Biol. 2006;26:4111-21. 
33. Pick L, Schier A, Affolter M, Schmidt-Glenewinkel T, Gehring WJ. Analysis of the ftz upstream element: germ layer-specific enhancers are independently autoregulated. Genes Dev. 1990;4:1224-39.

34. Shima Y, Zubair M, Komatsu T, Oka S, Yokoyama C, Tachibana T, et al. Pituitary homeobox 2 regulates adrenal 4 binding protein/steroidogenic factor-1 gene transcription in the pituitary gonadotrope through interaction with the intronic enhancer. Mol Endocrinol. 2008;22:1633-46.

35. Halvorson LM, Kaiser UB, Chin WW. Stimulation of luteinizing hormone beta gene promoter activity by the orphan nuclear receptor, steroidogenic factor-1. J Biol Chem. 1996;271:6645-50.

36. Keri RA, Nilson $\mathrm{JH}$. A steroidogenic factor-1 binding site is required for activity of the luteinizing hormone beta subunit promoter in gonadotropes of transgenic mice. J Biol Chem. 1996;271:10782-5.

37. lyer AK, Brayman MJ, Mellon PL. Dynamic chromatin modifications control $\mathrm{GnRH}$ gene expression during neuronal differentiation and protein kinase C signal transduction. Mol Endocrinol. 2011;25:460-73.

38. Iyer AK, Miller NL, Yip K, Tran BH, Mellon PL. Enhancers of GnRH transcription embedded in an upstream gene use homeodomain proteins to specify hypothalamic expression. Mol Endocrinol. 2010;24:1949-64.

39. Haring M, Offermann S, Danker T, Horst I, Peterhansel C, Stam M. Chromatin immunoprecipitation: optimization, quantitative analysis and data normalization. Plant Methods. 2007;3:11

40. Zhang H, Bailey JS, Coss D, Lin B, Tsutsumi R, Lawson MA, et al. Activin modulates the transcriptional response of LbetaT2 cells to gonadotropinreleasing hormone and alters cellular proliferation. Mol Endocrinol. 2006;20: 2909-30.

41. Coss D, Mellon PL, Thackray VG. A FoxL in the Smad house: activin regulation of FSH. Trends Endocrinol Metab. 2010;21:562-8.

42. McArthur M, Gerum S, Stamatoyannopoulos G. Quantification of DNaselsensitivity by real-time PCR: quantitative analysis of DNasel-hypersensitivity of the mouse beta-globin LCR. J Mol Biol. 2001;313:27-34.

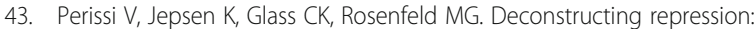
evolving models of co-repressor action. Nat Rev Genet. 2010;11:109-23.

44. Hon GC, Hawkins RD, Ren B. Predictive chromatin signatures in the mammalian genome. Hum Mol Genet. 2009;18:R195-201.

45. Barrera LO, Ren B. The transcriptional regulatory code of eukaryotic cellsinsights from genome-wide analysis of chromatin organization and transcription factor binding. Curr Opin Cell Biol. 2006;18:291-8.

46. Roybal LL, Hambarchyan A, Meadows JD, Barakat NH, Pepa PA, Breen KM, et al. Roles of binding elements, FOXL2 domains, and interactions with cJUN and SMADs in regulation of FSHbeta. Mol Endocrinol. 2014;28:1640-55.

47. McGillivray SM, Thackray VG, Coss D, Mellon PL. Activin and glucocorticoids synergistically activate follicle-stimulating hormone $\beta$-subunit gene expression in the immortalized L $\beta T 2$ gonadotrope cell line. Endocrinology. 2007;148:762-73.

48. Zhang Y, Fatima N, Dufau ML. Coordinated changes in DNA methylation and histone modifications regulate silencing/derepression of luteinizing hormone receptor gene transcription. Mol Cell Biol. 2005;25:7929-39.

49. Ooi GT, Tawadros N, Escalona RM. Pituitary cell lines and their endocrine applications. Mol Cell Endocrinol. 2004;228:1-21.

50. Sanz E, Yang L, Su T, Morris DR, McKnight GS, Amieux PS. Cell-type-specific isolation of ribosome-associated mRNA from complex tissues. Proc Natl Acad Sci U S A. 2009:106:13939-44.

51. Hoffmann HM, Tamrazian A, Xie H, Perez-Millan MI, Kauffman AS, Mellon PL. Heterozygous deletion of ventral anterior homeobox (Vax1) causes subfertility in mice. Endocrinology. 2014;155:4043-53.

52. Zhao Y, Zhu M, Yu Y, Qiu L, Zhang Y, He L, et al. Brain REST/NRSF Is Not Only a Silent Repressor but Also an Active Protector. Mol Neurobiol. 2017; 54:541-50.

53. Ichiyanagi K. Epigenetic regulation of transcription and possible functions of mammalian short interspersed elements, SINEs. Genes Genet Syst. 2013;88:19-29.

54. Magotra A, Naskar S, Das B, Ahmad T. A comparative study of SINE insertion together with a mutation in the first intron of follicle stimulating hormone beta gene in indigenous pigs of India. Mol Biol Rep. 2015;42:465-70.

55. Coss D, Hand CM, Yaphockun KK, Ely HA, Mellon PL. P38 mitogen-activated protein kinase is critical for synergistic induction of the FSH(beta) gene by gonadotropin-releasing hormone and activin through augmentation of cFos induction and Smad phosphorylation. Mol Endocrinol. 2007;21:3071-86.

56. Lim S, Luo M, Koh M, Yang M, bin Abdul Kadir MN, Tan JH, et al. Distinct mechanisms involving diverse histone deacetylases repress expression of the two gonadotropin beta-subunit genes in immature gonadotropes, and their actions are overcome by gonadotropin-releasing hormone. Mol Cell Biol. 2007;27:4105-20.

57. Burger LL, Haisenleder DJ, Aylor KW, Marshall JC. Regulation of intracellular signaling cascades by GNRH pulse frequency in the rat pituitary: roles for CaMK II, ERK, and JNK activation. Biol Reprod. 2008;79:947-53.

58. Haisenleder DJ, Burger LL, Walsh HE, Stevens J, Aylor KW, Shupnik MA, et al. Pulsatile gonadotropin-releasing hormone stimulation of gonadotropin subunit transcription in rat pituitaries: evidence for the involvement of Jun N-terminal kinase but not p38. Endocrinology. 2008;149:139-45.

59. Dalkin AC, Haisenleder DJ, Ortolano GA, Ellis TR, Marshall JC. The frequency of gonadotropin-releasing-hormone stimulation differentially regulates gonadotropin subunit messenger ribonucleic acid expression. Endocrinology. 1989;125:917-24.

60. Haisenleder DJ, Katt JA, Ortolano GA, el Gewely MR, Duncan JA, Dee C, et al. Influence of gonadotropin-releasing hormone pulse amplitude, frequency, and treatment duration on the regulation of luteinizing hormone (LH) subunit messenger ribonucleic acids and LH secretion. Mol Endocrinol. 1988;2:338-43.

61. Papavasiliou SS, Zmeili S, Khoury S, Landefeld TD, Chin WW, Marshall JC. Gonadotropin-releasing hormone differentially regulates expression of the genes for luteinizing hormone alpha and beta subunits in male rats. Proc Natl Acad Sci U S A. 1986:83:4026-9.

62. Buenrostro JD, Giresi PG, Zaba LC, Chang HY, Greenleaf WJ. Transposition of native chromatin for fast and sensitive epigenomic profiling of open chromatin, DNA-binding proteins and nucleosome position. Nat Methods. 2013:10:1213-8

63. Mullen RD, Colvin SC, Hunter CS, Savage JJ, Walvoord EC, Bhangoo AP, et al Roles of the LHX3 and LHX4 LIM-homeodomain factors in pituitary development. Mol Cell Endocrinol. 2007;2:190-5.

64. Tremblay JJ, Lanctôt C, Drouin J. The pan-pituitary activator of transcription, Ptx1 (pituitary homeobox 1), acts in synergy with SF-1 and Pit1 and is an upstream regulator of the Lim-homeodomain gene Lim3/Lhx3. Mol Endocrinol. 1998:12:428-41.

65. Sheng HZ, Zhadanov AB, Mosinger BJ, Fujii T, Bertuzzi S, Grinberg A, et al. Specification of pituitary cell lineages by the LIM homeobox gene Lhx3. Science. 1996;272:1004-7.

66. Charles MA, Mortensen AH, Potok MA, Camper SA. Pitx2 deletion in pituitary gonadotropes is compatible with gonadal development, puberty, and fertility. Genesis. 2008;46:507-14.

67. Tremblay JJ, Drouin J. Egr-1 is a downstream effector of GnRH and synergizes by direct interaction with Ptx1 and SF-1 to enhance luteinizing hormone $\beta$ gene transcription. Mol Cell Biol. 1999;19:2567-76.

68. Fortin J, Lamba P, Wang Y, Bernard DJ. Conservation of mechanisms mediating gonadotrophin-releasing hormone 1 stimulation of human luteinizing hormone beta subunit transcription. Mol Hum Reprod. 2009;15:77-87.

69. Cederberg RA, Smith JE, McDonald EA, Lee C, Perkins AR, White BR. Activity of the porcine gonadotropin-releasing hormone receptor gene promoter is partially conferred by a distal gonadotrope specific element (GSE) within an upstream enhancing region, two proximal GSEs and a retinoid $X$ receptor binding site. Reprod Biol Endocrinol. 2015;13:45.

70. Jacobs SB, Coss D, McGillivray SM, Mellon PL. Nuclear factor $Y$ and steroidogenic factor 1 physically and functionally interact to contribute to cell-specific expression of the mouse Follicle-stimulating hormone-beta gene. Mol Endocrinol. 2003;17:1470-83.

71. West BE, Parker GE, Savage JJ, Kiratipranon P, Toomey KS, Beach LR, et al. Regulation of the follicle-stimulating hormone beta gene by the LHX3 LIMhomeodomain transcription factor. Endocrinology. 2004;145:4866-79. 